\title{
Biofuel: A Ray of Hope for Sustainable Future
}

Jitendra Kumar Saini ${ }^{*}$

DBT-IOC Centre for Advanced Bioenergy Research, Indian Oil Corporation Limited, Research \& Development Centre, Sector-13, Faridabad, Haryana-121007, India

*Corresponding author: Saini JK, DBT-IOC Centre for Advanced Bioenergy Research, Indian Oil Corporation Limited, Research \& Development Centre, Sector-13, Faridabad, Haryana-121007, India, Tel: +91-9971958118; E-mail: me_jk@rediffmail.com

Received date: May 21, 2015; Accepted date: May 22, 2015; Published date: May 29, 2015

Copyright: (c) 2015 Saini. This is an open-access article distributed under the terms of the Creative Commons Attribution License, which permits unrestricted use, distribution, and reproduction in any medium, provided the original author and source are credited.

\section{Introduction}

Recently in 2012, global emissions of $\mathrm{CO}_{2}$ industries increased at the rate of only $1.1 \%$ (downward $0.3 \%$ correction for leap year) in comparison to the average of $2.9 \%$ for the last decade. Major source of this emission is combustion of fossil-fuel and that coming from smaller industries. Some of the major $\mathrm{CO}_{2}$ emitting countries of the world i.e. United States, EU, Russian Federation and Japan saw a decrease in $\mathrm{CO}_{2}$ emission in 2012 by $4 \%, 1.6 \%, 1 \%$, and $6 \%$, respectively. Energy-related human activities needed for economic growth during the past decade, were the major cause of $\mathrm{CO}_{2}$ emission, especially in developing countries of the globe. But the reduced emission rates in 2012 due to the uncoupling of the $\mathrm{CO}_{2}$ emissions increase and global economic growth (in GDP) can be seen as first sign of slowdown in the global $\mathrm{CO}_{2}$ emissions increase due to less fossilfuel intensive activities, more use of renewable and biofuel/bioenergy and increased energy saving. Therefore, further decrease in the global $\mathrm{CO}_{2}$ emission is possible only if the major $\mathrm{CO}_{2}$ contributing countries as well as fast growing economies of the world make more use of clean and renewable energy resources, including biofuels and bioenergy.

Biofuels generally refer to liquid transportation fuels such as bioethanol and biodiesel. Their production and use has the potential to decrease global greenhouse gas emissions. Moreover, their use as additives can decrease our dependence upon petroleum based fossil fuels and can also improve the local employment opportunities for farmers. In contrast to the other renewable energy sources, biomass can be converted directly into biofuels. Ethanol (ethyl alcohol) is most commonly made by fermenting any carbohydrate (sugar, cellulose or starch) rich biomass through a process similar to beer brewing. Today, more focus is on ethanol production from cheap and abundant lignocellulosic biomass rich in cellulose and hemicellulose (the fibrous material of the plant biomass). More reliance on renewable biofuel resources is expected to help in the move towards a sustainable revolution. Though there have been debates over the food versus fuel controversies and other negative impacts of biofuels but recent technological breakthroughs in lignocellulose to bioethanol, third generation biodiesel and bio-hydrogen production using the lignocellulosic agro/forestry wastes are definitely a ray of hope for sustainable development. A clear picture of the role of biofuels in this aspect will also require more socio-economic studies highlighting the cost/benefit analysis of biofuels in long runs.

At present the efforts needed in bioenergy are substantially lesser than that needed for making biofuel/bioenergy as an important platform for various activities ultimately leading towards growth in sustainable manner. Timely efforts by the policy makers for large scale bioenergy production are the need of hour so that our coming generations can enjoy the healthy nature and do not have limitations of the non-renewable energy resources such as petroleum based fuels. 